\title{
Retraction Note: Late phase activation of nuclear transcription factor kappaB by doxorubicin is mediated by interleukin-8 and induction of apoptosis via FasL
}

Charitha Gangadharan • Maikho Thoh •

Sunil Kumar Manna

Published online: 24 March 2013

(C) Springer Science+Business Media New York 2013

Retraction to: Breast Cancer Res Treat (2010)

\section{0:671-683}

DOI 10.1007/s10549-009-0493-z

This article has been retracted at the request of the Centre for DNA Fingerprinting and Diagnostics as it contains manipulated figures.

The online version of the original article can be found under doi:10.1007/s10549-009-0493-z.

C. Gangadharan · M. Thoh · S. K. Manna ( $₫)$

Laboratory of Immunology, Centre for DNA Fingerprinting

\& Diagnostics, Nampally, Hyderabad 500001, India

e-mail: manna@cdfd.org.in 